(c) 2010 IEEE. Personal use of this material is permitted. Permission from IEEE must be obtained for all other uses, in any current or future media, including reprinting/republishing this material for advertising or promotional purposes, creating new collective works, for resale or redistribution to servers or lists, or reuse of any copyrighted component of this work in other works. 


\title{
An Aboriginal English Ontology Framework for Patient-Practitioner Interview Encounters
}

\author{
David Forbes, Amandeep Sidhu, Jaipal Singh \\ Digital Ecosystem and Business Intelligence Institute \\ Curtin University of Technology \\ Perth, Australia \\ david.e.forbes@postgrad.curtin.edu.au, \{a.sidhu, j.singh\}@curtin.edu.au
}

\begin{abstract}
Current diagnosis, treatment and healthcare delivery processes in Australia are dominated by long established westernized clinically driven methods of patient-practitioner interaction. Consequently this dominant healthcare provider influence contributes to risk of miscommunication, misinformation in patient records and reciprocal misunderstandings that go unrecognised as such. For Indigenous communities, inadequate health literacy (HL) and a pervasive semantic disconnect are major barriers. Overcoming these barriers in the primary care setting presents opportunities to deliver appropriate timely and more effective care. We propose an e-health framework that enhances the Patient-Practitioner Interview Encounter (PPIE) through the use of a patient-centric linguistic interface using semantic mappings between Aboriginal English (AE) and Standard Australian English (SAE). This will ameliorate communications and interactions, so meeting the needs of all stakeholders (Patients, Physicians, Nurses, Allied Health Professionals and their Non-Critical Carers) engaged in Indigenous patient-centric primary care. It provides healthcare practitioners and their Indigenous T2DM patients with a new platform for two-way educative sharing and knowledge exchange that will increase mutually productive treatment, care and management expectations.
\end{abstract}

\section{Introduction}

From a videotaped clinical interaction study involving volunteer Aboriginal patients Cass et al. demonstrated that miscommunication is pervasive, and that trained interpreters provide only a partial solution. In-depth post-clinical interaction interviews of individual patients and health workers showed that a shared understanding of key concepts was rarely achieved and miscommunication often went unrecognized[1].

Miscommunication is not uncommon within professional groups, even those where cultural and language differences are ostensibly absent. Doctors and nurses struggle with a vocabulary which is accommodating an ever-growing clinical terminology system replete with acronyms. The vocabulary of medicine has its roots in Greek, Latin and Norman wordage, littered with complex labels and strings added over time as the science of medicine has evolved; and technological change has brought new nouns, adjectives and verbs to the lexicon. The Mayo Clinic is heading-up the effort to produce the $11^{\text {th }}$ revision of the International Statistical Classification of Diseases and Related Health Problems (ICD), scheduled for release in 2015[2]. The previous $10^{\text {th }}$ edition was published in 1992 when the worldwide web was only just beginning to emerge. The new edition work is focused on simplifying and codifying linguistic variation, abbreviations, and synonyms so that standardized recording and transactional detail becomes semantically consistent and valuable to professional practitioners and patients.

The prospect is that a healthcare practitioner will quickly identify keywords and thereby instantly access guidance for those treatments that have worked the best, statistically, for other patients with similar complaints around the world.

The ICD work however is predicated on a fairly high audience and user level of health literacy and does not necessarily offer a direct solution where health literacy barriers impede the quality and value of PPIE. Notwithstanding this, it will ultimately represent a valid source for the formal import of medical domain thesauri in the process of PPIE ontology mapping and 
semantic layering. There is however a high risk that the pace of change represented by ICD-11 will further exacerbate the 'digital divide' that adversely affects Indigenous communities already disadvantaged through low levels of engagement with ICT and limited health literacy.

\section{Background}

\section{The Semantic Divide}

Within the PPIE involving Aboriginal patients, the meaning of statements made by patients and practitioners may at times be ambiguous. If unrecognized, that ambiguity may impose harm or at least a less than effective healthcare outcome. There is also another potentially hidden bifurcation of semantics in the PPIE. Trudgen has alluded to it in his book [3] when he discusses historic failures of practitioners to discover and use ways of explaining the reasons that certain physical ailments occur and equally the reasons for pursuing specific treatments and medications. If a patient wishes to know and is prepared to ask what a piece if diagnostic information 'means', the likely response will be a clinically based explanation. If that explanation is also accompanied with a prognosis, a second 'meaning' is conveyed. In other words, "what does this mean?" becomes synonymous with "what are the implications for my future health?" These examples also simplistically skate over the AE and SAE communications and barriers and circumstantial realities.

Ontologies and their applications

The World Wide Web Consortium (W3C) offers one of the more coherent definitions of ontology: $A n$ ontology defines the terms used to describe and represent an area of knowledge. Ontologies are used by people, databases, and applications that need to share domain information (a domain is just a specific subject area or area of knowledge, like medicine, tool manufacturing, real estate, automobile repair, financial management, etc.). Ontologies include computer-usable definitions of basic concepts in the domain and the relationships among them. [4]. A substantial part of ontology development comes from lexicography; but as discussed, communication is not about words alone. Cultural differences within the specialized dynamics of health care interactions can often combine with the influence of 'power distance' to devalue patient participation in the dialogue. Physicians generally still favour face-to-face interviews with their patients; but practicalities and a host of social factors are inviting other options. Studies of ontology applications potential include fixed and mobile conversational support tools, automated clinical guideline services, personalization of patient treatments and care, self-management and home care help systems [5-10].

Anatomical and physiological experiences, feelings and conditions perceived and described by patients as a routine part of westernized primary care practice symptom identification and diagnoses are not commonly volunteered in a comparable manner by Aboriginal patients and often do not translate reliably when they are discussed [3]. Western medicine explanations of the organs and the functions of the body have no equivalent perception, thereby complicating the dialogue of T2DM diagnosis, treatment and care. It is the communication of diagnosis, treatment and care, not the health care process itself that needs to be changed as illustrated by Lowell[11]. It is proposed therefore that in the professional clinical aspect of the dialogue, the ontology can only rely upon mapping SAE diabetes guidelines to the new AE ontology. A matching and mapping process is therefore required so that the parties to the dialogue both share the same understanding. Inversely, the AE dialogue ontology, mapped to SAE clinical reporting, will be used to inform and advise various concerned local and remote healthcare practitioners/entities. This advice and information may include patient and family AEgenerated responses, while preserving clinical meaning and healthcare value. In sum, the process objective is semantic interoperability. It is therefore vital that semantic translation accuracy is anticipated and protected throughout the design process. Semantics alone however are not the only challenge. Any ontology serving this function will require interoperability with a syntactic layer capable of dutifully representing the context of the cross-cultural dialogue.

\section{Methodology}

The pivotal focus of the sociolinguistic effort and pragmatics contribution to the dialogue ontologies will be T2DM diagnosis, treatment and care. The principal aim for the T2DM ontology is the application of clinically approved guidelines to navigate through diagnosis, treatments, and care working with and within established Australian national clinical care guidelines. These will eventually map to PPIE conversational modality guidelines in the AE ontology. Australian General Practice and practitioner training and published guidelines are consistent for diagnosed T2DM patients[12-14]. In our preparatory research, we 
are collaborating with diabetes educators, chronic disease program advisors, Aboriginal education health and nurse training groups, and Aboriginal literacy experts. We are also able to merge the guidelines with several complementary accredited paper and multimedia education and training products. These are contemporary communications tools from dedicated Aboriginal diabetes management programs, an Aboriginal nurse training package provided by a Certified Diabetes Educator (CDE) and both teaching and student classroom materials focused on elevation of Aboriginal English as a valued dialectal instrument.

The modeling approach for the ontologies effectively borrows certain features from the work of others (Sidhu[15], Meersman [16], Ng and Wong [17] and Barrett[5]) notably because of the common applications characteristics of language translation in the healthcare environment. This model however is more focused on the combination of semantics and behavioral pragmatics than on written and spoken word translation and formal grammar construction. There is a slight interface benefit from its ultimate user conversational modality which represents a hybrid/derivative lexical relationship; but complexity prefaces this objective when a number of cultural interaction barriers are encountered.

Aboriginal English Ontology

The Aboriginal English AE ontology tree is also prepared with the mapping to SAE T2DM clinical guidelines in mind. Figure 1 gives the upper class scope, extending into subclasses shown in figures 2 through 6. These are expressive of the complexity at play within the cognitive processes and socio-cultural differences between Aboriginal AE speakers and nonIndigenous SAE speakers.

Community Healthcare Ontology for T2DM

Figure 7 presents the full healthcare ontology tree. It should be noted that the directional influence of the healthcare ontology is toward the specific chronic

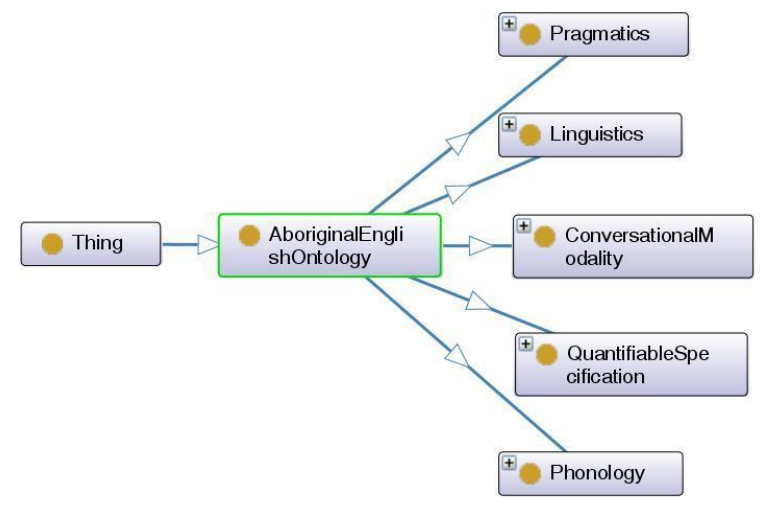

Figure 1 Aboriginal English Ontology

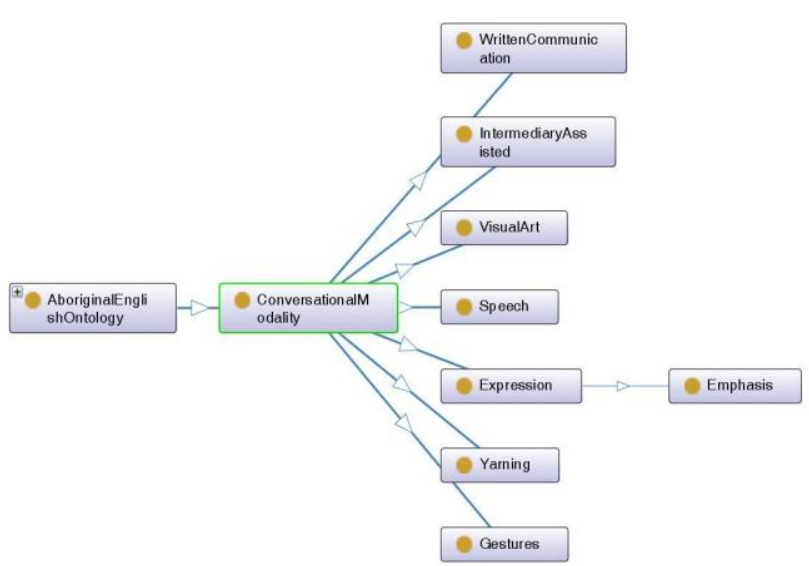

Figure 2 AE conversational modality

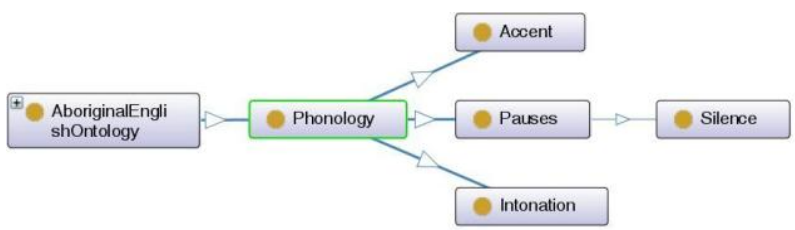

Figure 3 Phonology (hearing, sound)

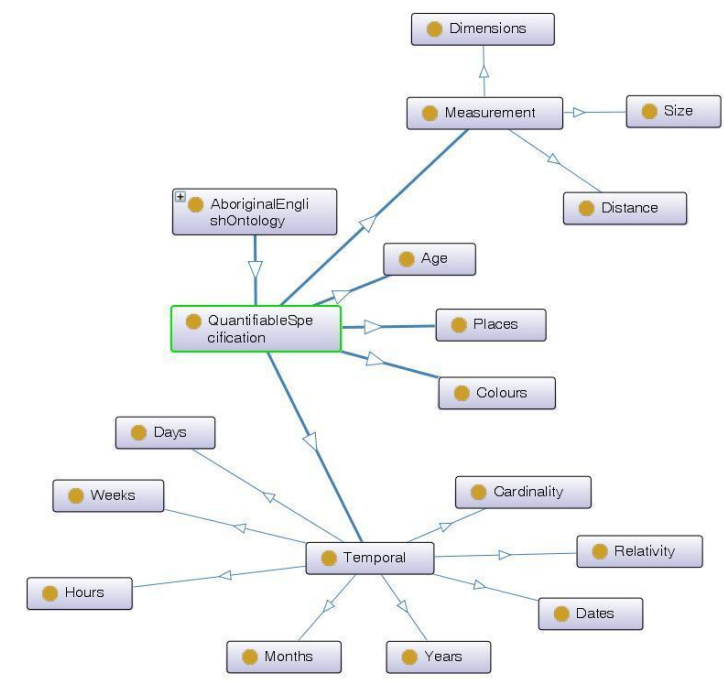

Figure 4 Quantifiable specification (measurement)

disease of T2DM with an intention to map to Aboriginal English. Therefore the subclass properties are clinically biased toward Aboriginal T2DM relationships.

\section{Discussion}

In our early reviews of $\mathrm{AE}$ we have discovered an infinite and intricate combination of semantic, syntactic and pragmatic challenges with many permutations of 


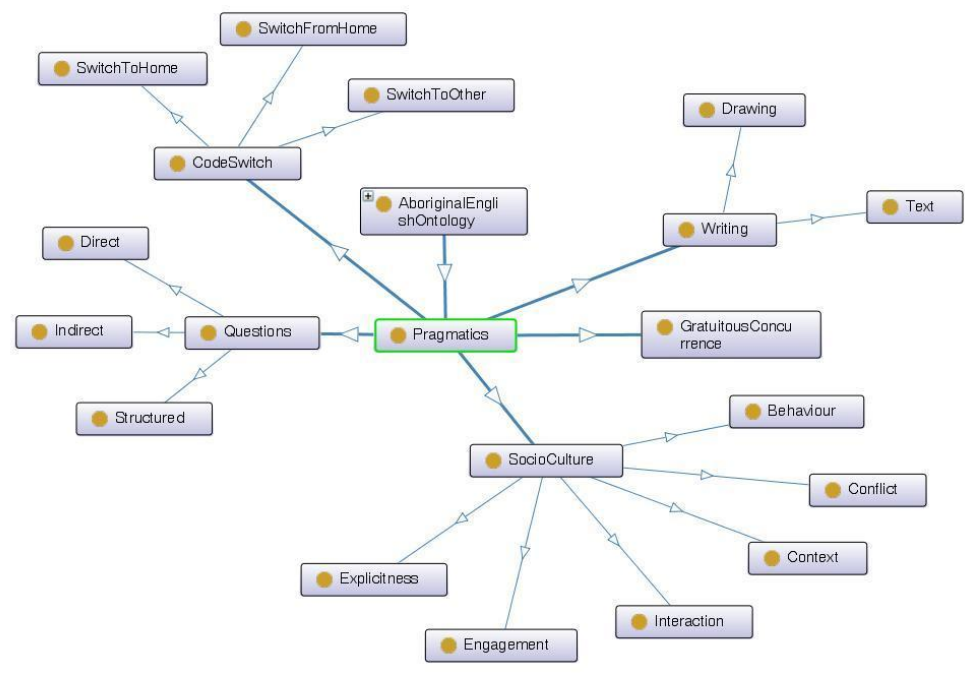

Figure 5 Pragmatics

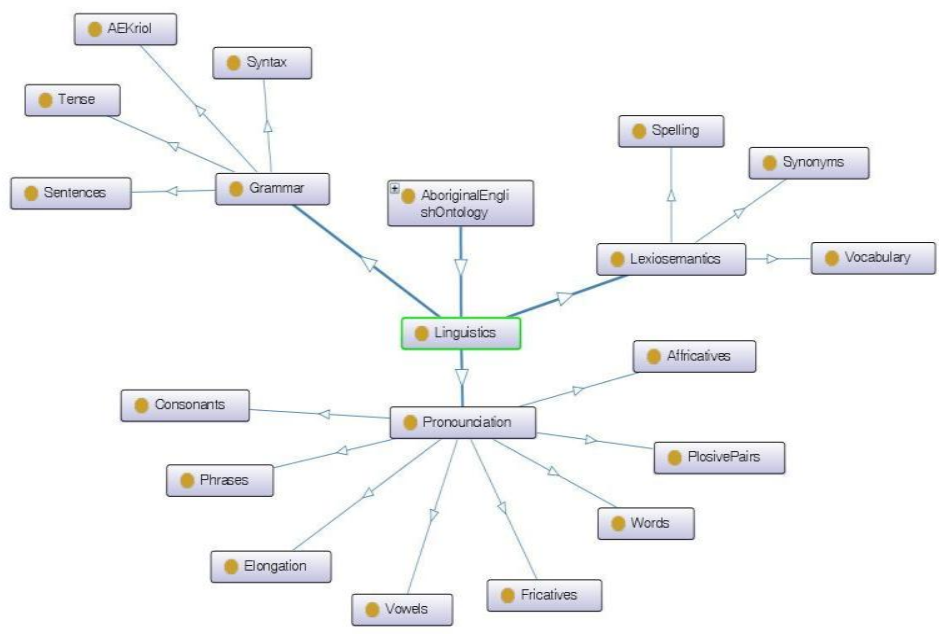

Figure 6 AE linguistics

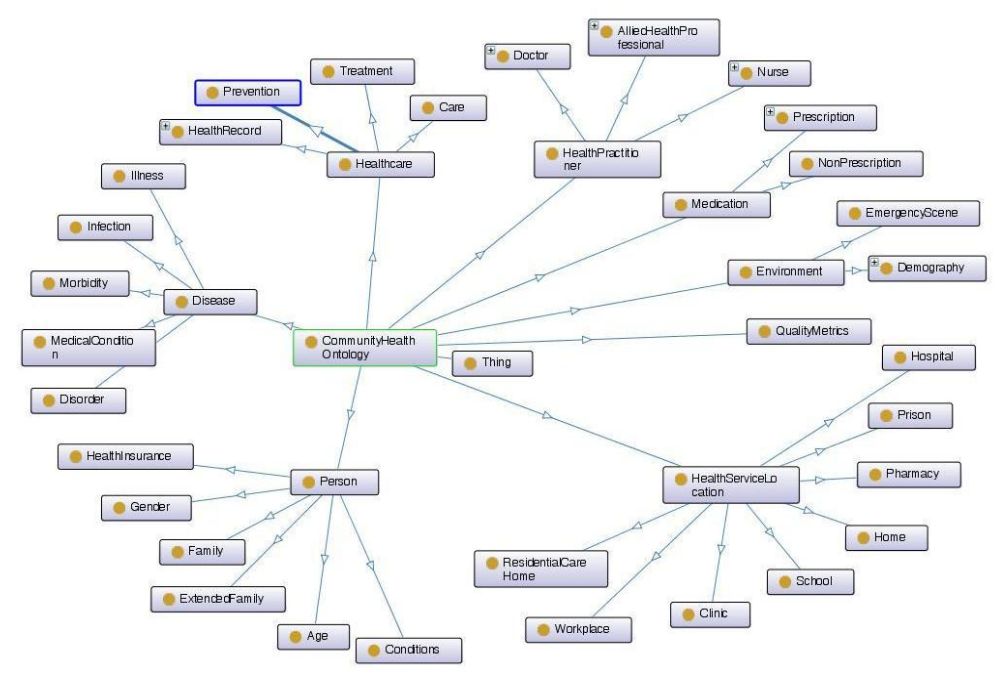

Figure 7 Community Healthcare Ontology 
linguistic patterns. Table 1 provides a data sample, giving a variety of representational types that may influence the conversational modality within the PPIE.

The consonant patterns mentioned above may vary regionally; and in the third one listed, we see the common word initial change so that $\mathrm{AE}$ pronunciation differs, with ' $b$ ', ' $p$ ' = ' $v$ ', ' $\mathrm{f}$ ' in SAE. AE also commonly applies change to word class, in the instance shown the SAE noun becomes an AE verb. Irregular verbs are commonly formed via analogy with regular verb forms as shown with the word 'catched' equating to the past tense 'caught'. The copula; e.g. is, am, is not required in $\mathrm{AE}$. Transitive object marking applies to verbs that are sometimes marked for having an object (a noun to follow). Measurement of space and time is typically non-specific. Expression of quantity uses sound effects, usually with elongation. All AE past tense words are frequently made to look like the first (person singular). Redundancy marking frequently occurs as a marker of previous or assumed information which is not repeated. 'What' replaces 'why in many interrogative sentences. Plural marker ' $\mathrm{s}$ ' is not always used but may be used when there is no quantification. The second person pronoun may use the plural marker 's'.

One of the several challenges is the creation of sufficient fluidity in the function and relational aspects of the ontologies. The embedded discipline of existing clinical guideline compliance for instance infers a chrono-linear step by step checklist process, while recognising variables that will create deviations and diversions. Effectively the AE PPIE support model will anticipate and accommodate more diversionary influences, partly illustrated by the AE data sampling above and perhaps in contrast to past practices and preferences of healthcare practitioners.

\section{References}

[1] A. Cass, et al., "Sharing the true stories: improving communication between Aboriginal patients and healthcare workers.," Medical Journal of Australia vol. 176, pp. 466-70., 2002.

[2] J. Barlow. (2009) Creating a Universal Medical Language for WHO Mayo Clinic. Discovery's Edge. Available: http://discoverysedge.mayo.edu/de09-2chute/

[3] R. Trudgen, Why Warriors Lie Down and Die. Parap, NT: Aboriginal Resource and Development Services Inc. , 2000.

[4] (2004, 11 November 2010). What /s An Ontology? Available: http://www.w3.org/TR/2004/REC-webontreq-20040210/\#onto-def

[5] L. Barrett, "Designing an Ontology of Dialogue Elements Modeling Doctor-Patient Exchanges" in
Table 1: Comparison of selected Aboriginal English pragmatic syntax and Standard Australian English. Selected sources: [18-21]

\begin{tabular}{|c|c|c|}
\hline $\begin{array}{l}\text { Syntactic/Pragmatic } \\
\text { role/relevance }\end{array}$ & $\begin{array}{l}\mathrm{AE} \\
\text { representation }\end{array}$ & $\begin{array}{l}\text { SAE } \\
\text { comparison }\end{array}$ \\
\hline Word & Camp & Home \\
\hline Word & Mob & Group \\
\hline Word & Lingo & $\begin{array}{l}\text { Aboriginal } \\
\text { language }\end{array}$ \\
\hline Words/phrase & Sorry business & $\begin{array}{l}\text { Ceremony } \\
\text { associated } \\
\text { with death }\end{array}$ \\
\hline Words/phrase & $\begin{array}{l}\text { Grow (a child) } \\
\text { up }\end{array}$ & Raise (a child) \\
\hline Word & Growl & Scold \\
\hline Word & Gammon & $\begin{array}{l}\text { Pretending, } \\
\text { kidding }\end{array}$ \\
\hline Word & Cheeky & $\begin{array}{l}\text { Mischievous, } \\
\text { aggressive, } \\
\text { dangerous }\end{array}$ \\
\hline Word & Solid & Fantastic \\
\hline Phrase & To tongue for & To long for \\
\hline Pronunciation & Enry's at & Henry's hat \\
\hline Consonant pattern & Dere & There \\
\hline Consonant pattern & Dat & That \\
\hline Consonant Pattern & Bight & Fight \\
\hline Word class change & Don't liar dad & Do not lie dad \\
\hline Irregular verb use & $\begin{array}{l}\text { We catched } \\
\text { snakes }\end{array}$ & $\begin{array}{l}\text { We caught } \\
\text { some snakes }\end{array}$ \\
\hline Zero verb 'To be' & Dey poisonous & $\begin{array}{l}\text { They are } \\
\text { poisonous }\end{array}$ \\
\hline $\begin{array}{l}\text { Transitive Object } \\
\text { marking }\end{array}$ & $\begin{array}{l}\text { Dey catchem } \\
\text { fish }\end{array}$ & $\begin{array}{l}\text { They catch } \\
\text { fish }\end{array}$ \\
\hline $\begin{array}{l}\text { Transitive Object } \\
\text { marking }\end{array}$ & $\begin{array}{l}\text { Then when em } \\
\text { startem up dat } \\
\text { motor }\end{array}$ & $\begin{array}{l}\text { Then when } \\
\text { they start the } \\
\text { car engine }\end{array}$ \\
\hline Quantification & $\begin{array}{l}\text { An dere was a } \\
\text { bi-i-ig mob dere }\end{array}$ & $\begin{array}{l}\text { There was a } \\
\text { large group } \\
\text { of (people } \\
\text { etc) there }\end{array}$ \\
\hline Tense & We was & We were \\
\hline $\begin{array}{l}\text { Redundancy } \\
\text { marking }\end{array}$ & Ding & Thing \\
\hline Question forms & $\begin{array}{l}\text { What are you } \\
\text { cutting dat, you } \\
\text { cut dem small } \\
\text { or sumpin? }\end{array}$ & $\begin{array}{l}\text { Why are you } \\
\text { cutting that? } \\
\text { Are you } \\
\text { cutting them } \\
\text { into small } \\
\text { pieces? }\end{array}$ \\
\hline Plural marking & $\begin{array}{l}\text { We seen lots of } \\
\text { snake. } \\
\text { I seen youse. } \\
\text { We see } \\
\text { monkeys. }\end{array}$ & $\begin{array}{l}\text { We saw many } \\
\text { snakes. } \\
\text { I saw you. } \\
\text { We saw some } \\
\text { monkeys. }\end{array}$ \\
\hline
\end{tabular}


LREC 2006 Workshop on Acquiring and Representing Multilingual, Specialized Lexicons: the Case of Biomedicine, Genova, Italy, 2006.

[6] S. C. Bailin and H. B. Lehmann, "Facilitating Physician-Patient Dialogue through Ontology Negotiation," in 16th IEEE Symposium on ComputerBased Medical Systems (CBMS'03), New York, NY, 2003, p. p 248.

[7] A. Kumara and B. Smith, "Ontology for task-based clinical guidelines and the theory of granular partitions," in 9th Conference on Artificial Intelligence in Medicine Europe (AIME 2003) Berlin, 2003.

[8] A. Kumar, et al., "An ontological framework for the implementation of clinical guidelines in health care organizations.," Stud Health Technol Inform. , pp. 95107, 2004.

[9] T. Bickmore and T. Giorgino "Health dialog systems for patients and consumers," Journal of Biomedical Informatics, vol. 39, pp. 556 - 5712006.

[10] S. Kim and Jae-gu-Song, "A Study on Ontology Based Medical Information System for Home Healthcare," in Proceedings of the 2007 International Conference on Intelligent Pervasive Computing, South Korea, 2007.

[11] A. Lowell. (1998, 12 November 2009). Cultural Knowledge in Aboriginal Health Care. A review of two subprograms of the Cooperative Research Centre for Aboriginal and Tropical Health's Indigenous Health and Education Research program Available: http://www.crcah.org.au/publications/downloads/Com munication and Cultural.pdf

[12] "Diabetes Management in General Practice Guidelines for Type 2 Diabetes " Diabetes Australia The Royal Australian College of General Practitioners November 20092009.

[13] "Diabetes Model of Care," Department of Health Western Australia, Endocrine Health Network Ed., ed. Perth, 2008.
[14] "Type 2 Diabetes Mellitus Guideline Series," ed. Curtin ACT: Rural Health Education Foundation, 2009.

[15] A. S. Sidhu, et al., "Current Status of Biomedical Ontologies: Developments in 2006," in 2007 IEEE International Conference on Digital Ecosystems and Technologies, Cairns, Australia, 2007, pp. 581-585.

[16] R. Meersman, "Semantic Ontology Tools in IS Design," in 11th International Symposium on Methodologies for Intelligent Systems (ISMIS 1999), Warsaw, Poland, 1999, pp. 30-45.

[17] S. C. S. W. Ng and A. K. Y. Wong, "RCR - A Novel Model for Effective Computer-Aided TCM (Traditional Chinese Medicine) Learning over the Web," presented at the 2008 International Conference on Computer Science and Software Engineering Wuhan, China 2008

[18] D. Eades. (ND, 19 Nov 2009). Aboriginal English. Available: http://www.une.edu.au/langnet/definitions/aboriginal.ht $\mathrm{ml}$

[19] I. G. Malcolm, et al., Two-Way English: Towards More User-Friendly Education for Speakers of Aboriginal English. Mount Lawley: Centre for Applied Language and Literacy Research, Edith Cowan University and Education Department of W.A., 1999.

[20] D. Eades. (1993 Reprinted 2000, 14 November 2009). Pen 93: Aboriginal English. Available: http://www.elit.edu.au/mediaLibrary/documents/pens/P EN93.pdf

[21] Y. Haig, et al. (2005, 7 November 2009). Pen 150: Teaching students who speak Aboriginal English. Available:

http://www.elit.edu.au/mediaLibrary/documents/pens/P EN150.pdf 